\title{
Commission de Finance
}

La Commission de Finance propose à l'Assemblée générale:

I. Que les subventions suivantes soient allouées pour la période s'écoulant du Ier janvier r956 au 31 décembre I958:

\section{(a) Subventions annuelles}

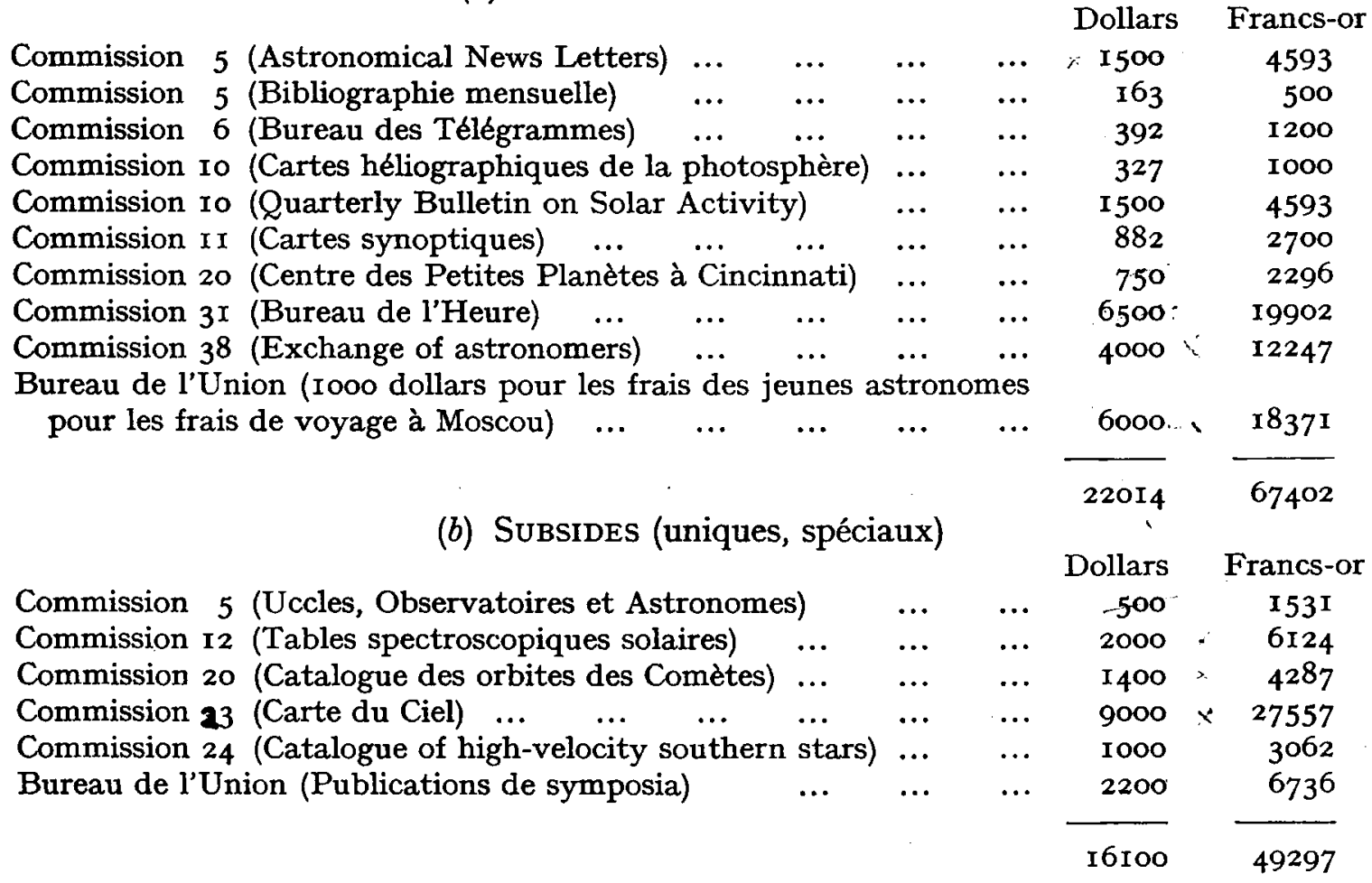

2. Que l'unité de cotisation pour les années 1956 , I957, I958 reste fixée à 500 francs-or.

Commission 3

\section{RECOMMANDATIONS}

I. La Commission recommande la notation $\mathrm{cm} \cdot .^{-1}$ pour le Kayser.

2. La Commission recommande l'emploi de la notation A pour l'angstrom toutes les fois que la confusion avec une autre grandeur est impossible et l'emploi de la notation A dans les autres cas.

3. La Commission a recommandé que pour l'abréviation des noms des constellations soit définitivement adoptée la forme à trois lettres.

4. La Commission recommande l'emploi des symboles figurant dans le tableau de la p. $23 \mathrm{du}$ Draft Report. On tiendra compte que, par suite d'une erreur typographique à la première ligne, la lettre $\kappa$ (kappa) doit être remplacée par $r$. Il sera précisé qu'à la dernière ligne la composante $\Pi$ (grand pi) de la vitesse doit toujours être comptée positivement vers l'extérieur. (Voir aussi page 78 de ce volume.)

\section{Commission 5}

I. La Commission 5 prie instamment les institutions et les personnes publiant un travail concernant l'astronomie de bien vouloir en faire parvenir au moins un exemplaire, aussi rapidement que possible et sans passer par les lents services généraux de distribution, aux adresses ci-après, des bibliographies astronomiques.

(I) The Editor of the Astronomischer Jahresbericht. Astronomisches Rechen-Institut, I4 Grabengasse, Heidelberg, Germany. 